\title{
Screening Disability
}

\section{Brian Bergen-Aurand}

This issue of Screen Bodies features a Screen Shots section focusing on screening disability, including essays on new disability documentaries, vacillation and the dis/abled male body - especially as it plays out in Fred Zimmerman's 1950 film The Men - and questions of masquerade and representations of Richard III on stage and screen. It also includes general essays on "undoing" gender through complicity and subversion, the rise in the importance of the haptic in Japanese society, culture, and filmmaking in the 1920s, and an investigation of uncertainty and the "generosity paradox" with regard to gender, sexuality, and ability in cyborg cinema.

In "Something Outside of Ourselves: Crossing Boundaries in New Disability Documentary Cinema," Anna Debinski surveys the situations and tropes most commonly encountered in mainstream documentaries addressing disability. Then, through an analysis of two examples-Astra Taylor's Examined Life (2008) and Bonnie Sherr Klein's Shameless: The Art of Disability (2006) - she shows how some new disability documentary cinema encourages connection and intimacy alongside distance and alienation. Highlighting how these documentaries deploy these ambivalent spectatorial positions, Debinski argues that they call for a denaturalization of disability's Otherness and a more substantial cinematic (and social) appreciation of disabled bodies as a reflection of human diversity - an experience of disability as a different way of being in the world.

Looking at the role of vacillation - as a wavering or oscillating between stances - with regard to the male dis/abled body, Elisabeta Girelli also takes up the question of the effects and affects of undecidability involved in the cinematic experience. The Men, Marlon Brando's first film, is an ambiguous study of masculinity that is, at times, progressive and, at others, regressive in its display of normative and nonnormative embodiment and expressions of masculinity, sexuality, and community. Building on the work of key disability studies and gender and sexuality studies scholars, such as Robert McRuer, Martin Norden, Tobin Siebers, and Judith Butler, Girelli discusses the cultural construction of the postwar male body and the roles it serves in order to open up the multiple and subversive meanings of the film and discover the extent to which The Men offers a way of thinking about corporeal identity based on dissent. 
Finally, closing the Screen Shot section on disability, Lauren Coker examines the role of masquerade in Richard Loncraine's 1995 film adaptation of Richard III. Starting from Katherine Schaap William's reading of the play, Coker delves into the function of duplicity in the play, paying special attention to how Sir lan McKellen's Richard Gloucester claims both abled and disabled bodily positions in order to secure political power. Specifically, she argues, the film banks on juxtaposing two contradictory images of disability. While McKellen plays Richard as an impaired character who is unsuited to the throne and lacks all sexual potency, the images around him display his violence and aggressiveness - particularly in the form of exaggerated phallic symbols. Thus, Coker asserts, while the film often shows Richard masquerading disability, it also shows him masquerading ability, putting the two into play-one against the other-as different situations demand.

While not concentrating especially on disability, the general articles in this issue also touch on related questions of impairment and ability in their explorations of screen bodies. In his fine-grained long take on intimacy, normalcy, and sexuality in Her, Paul Walker explores interactions with difference, uncertainty, and what he describes as the "generosity paradox" - the movement by which we suspend disbelief and certainty in favor of a constructed potentiality not limited by preexistent knowledge or categories of authenticity and legitimacy -in order to reconsider the boundaries of what makes us human. Taking an interdisciplinary approach that develops concepts from rhetoric, philosophy, gender studies, disability studies, and queer theory, Walker investigates the fictional (filmic) radical alterity at the foundation of an un/certain, dis/abled being in the world. Through his reading of the characterizations within and critical reactions to Her, he shows how our "attempted respite from frustrating, confusing, and frightening interactions limits our voice, undermines difference, and favors a unifying persuasive intent, which more likely than not involves an attempt to change Others rather than allowing our mutual differences to generatively remain." In the end, his skepticism toward our rejection of inauthenticity, uncertainty, and difference raises questions about the role of coherence in how we define ourselves as human.

In the 1920 and 1930s, in the process of modernization, Japanese society went through a realignment of sense perception and a remapping of the body, one which called for the privileging of vision. Daisuke Miyao, in his article "Cinema and the Haptic in Modern Japan" delves into the dynamics of this period of realignment in order to show how many Japanese artists, writers, and filmmakers - all influenced by German expressionism - challenged this call to reorganize thinking about the body and the aesthetic-corporeal interaction. Looking at the cinema of that period, Miyao asks how contemporary filmmakers formulated a cinematic discourse for remapping the body during this period of flux, when the status of cinema within the arts and the wider culture was still 
uncertain. He compares and contrasts several authors-working in fiction and nonfiction (expository) - and several filmmakers to show the relation between art and criticism and to highlight those Japanese intellectuals who questioned the call to separate the senses and reorganize parameters of thinking about embodied experience. In the process, Miyao shows how these haptic thinkers were inspired by the German cinema screening in Japan at the time and how the haptics of this European aesthetic helped them problematize privileging the sense of vision, especially in this new audiovisual medium. Concentrating especially on the work of Sato Haruo, Ozu Yasujiro, and Iwasaki Akira, Miyao shows why we may have to consider Japanese modernization as both a haptic and a visual transformation.

In the opening article to this issue, "Undoing' Gender: Nexus of Complicity and Acts of Subversion in The Piano Teacher and the Black Swan," Neha Arora and Stephan Resch propose a controversial thesis regarding these films and their implications for understanding complicity, subversion, and women's contradictory roles under patriarchy. Responding to Haneke's and Aronofsky's films, Arora and Resch invoke Butler and Foucault to argue that we need to reconsider how male artists (filmmakers) and female artists (dancers and pianists) respond to social, aesthetic, and familial pressures. In these films, they claim, we find unorthodox women unorthodoxly struggling to navigate the discipline imposed upon them by both their artistic endeavors and their live-in mothers. Here, mothers serve as patriarchy's enforcers, and daughters resist the limits of patriarchy by defying their mothers. Furthermore, these films deploy a certain "audiovisual violence to exhibit the violence of society's gender norms and use gender-coded romance narratives to subvert society's gender codes." Thus, according to Arora and Resch, these films complicate any simple overturning of the accepted understanding of how patriarchy works, and '“do' feminism unconventionally by exposing the nexus of women's complicity with omnipresent societal power structures that safeguard gender norms." These films produce women as victims and perpetrators of violence and emphasize that our socially constructed gender ideology can only be destabilized by women doing their gender and sexuality differently, subversively.

As usual, this issue concludes with a number of reviews of significant works at the intersection of mediated corporeal experience, perception, and display. Tess S. Skadegård Thorsen reviews Katharina Lindner's Film Bodies: Queer Feminist Encounters with Gender and Sexuality in Cinema. A. Anthony responds to the essay collection Trap Door - Trans Cultural Production and the Politics of Visibility, edited by Reina Gossett, Eric A. Stanley, and Johanna Burton. Screen Bodies editorial board member Carmela Garritano reviews Affective Image: Postapartheid Documentary Perspectives by Marietta Kesting. And, finally, one of the Screen Bodies reviews editors, Steen Ledet Christiansen, appraises Saige Walton's Cinema's Baroque Flesh: Film, Phenomenology and the Art of Entanglement. 
Brian Bergen-Aurand teaches in the English Department at Bellevue College, Washington, where he specializes in film, ethics, embodiment, and humor studies. He is the founder and editor of Screen Bodies journal, editor of Comedy Begins with Our Simplest Gestures: Levinas, Ethics, and Humor (2017) and Transnational Chinese Cinema, Corporeality, Desire, and the Ethics of Failure (2014, with Mary Mazzilli and Hee Wai Siam), and the author of Cinematic Provocations: Ethics, Justice, Embodiment, and Global Film (forthcoming). Currently, he is developing (with Andrew Grossman) the Encyclopedia of Global Queer Cinema. Email: screenbodies@berghahnjournals.com 